Article

\title{
Biocatalytic Epoxidation of Cyclooctene to 1,2-Epoxycyclooctane by a Newly Immobilized Aspergillus niger Lipase
}

\author{
Qingsheng Chen, Fei Peng, Fangzhou Li, Gaohui Xia, Minhua Zong and Wenyong Lou * \\ Laboratory of Applied Biocatalysis, School of Food Science and Engineering, South China University of \\ Technology, Guangzhou 510640, China; qschen101@126.com (Q.C.); pengf0129@foxmail.com (F.P.); \\ lfzcd@163.com (F.L.); btghxia@foxmail.com (G.X.); btmhzong@scut.edu.cn (M.Z.) \\ * Correspondence: wylou@scut.edu.cn
}

Received: 20 June 2020; Accepted: 10 July 2020; Published: 13 July 2020

\begin{abstract}
A newly immobilized Aspergillus niger lipase (ANL@ZnGlu-MNPs) was employed for the preparation of 1,2-epoxycyclooctane by oxidation of cyclooctene. The chosen variables, including substrate concentration, reaction temperature, immobilized enzyme dose, and $\mathrm{H}_{2} \mathrm{O}_{2}$ dose, were optimized in the reaction system of ethyl acetate. The yield and the enantiomeric excess of the product were achieved at $56.8 \%$ and $84.1 \%$, respectively, under the following optimum reaction conditions: the concentration of substrate (cyclooctene) was $150 \mathrm{mM}$, the dosages of immobilized enzyme (ANL@ZnGlu-MNPs) and hydrogen peroxide were respectively $100 \mathrm{mg}$ and $4.4 \mathrm{mmol}$, and the reaction was carried out in the system of $4 \mathrm{~mL}$ ethyl acetate at $40{ }^{\circ} \mathrm{C}$. Further study on the operational stability of ANL@ZnGlu-MNPs showed that more than $51.6 \%$ of product yield was obtained after reusing for ten batches. A novel immobilized lipase was prepared and applied to synthesize 1,2-epoxycyclooctane from cyclooctene. Although ANL@ZnGlu-MNPs performs well in operational stability and the reaction can achieve high enantiomeric purity of the product, the yield of the catalytic reaction needs to be further improved.
\end{abstract}

Keywords: Aspergillus niger lipase; epoxidation reaction; cyclooctene; epoxides

\section{Introduction}

Epoxides are important functional intermediates, which play an active role in many fields such as pharmaceuticals [1,2], pesticides [3], cosmetics [2], and materials [4]. Phenyl glycidyl ether is widely used in the copolymerization with anhydride or lactone to synthesize linear polyesters, as well as ionic polymerization [5], and 1,2-epoxycyclooctane can be applied to prepare various derivatives of cyclooctane [6].

The use of biocatalysts in the synthesis of epoxides by olefins has received extensive attention due to mild reaction conditions, environmental friendliness, excellent selectivity, and sustainability [7]. Lipases show outstanding performance in many different kinds of reactions, for instance, hydrolysis, transesterification [8], and epoxidation [9]. Novoym 435 obtained by gene expression of Aspergillus oryzae has been widely used in various lipase-catalyzed epoxidation reactions due to its high efficiency [9-11]. Several olefins including cyclohexene, cyclooctene, and 1-octene can be epoxidized by lipase to achieve a high yield of corresponding product from $75 \%$ to $100 \%$ in ethyl acetate [12]. In addition, enzyme immobilization is necessary for the epoxidation of alkenes in systems containing strong oxidant and toxic organic solvent. With the application of nanotechnology used in enzyme immobilization, many delightful results have been achieved in the activity or the stability of biocatalyst. For example, Candida antarctica lipase B-inorganic crystal nanoflowers showed 25 times higher activity 
than the native lipase in the epoxidation of fatty acid [13]. Furthermore, the novel immobilized enzyme has better operational stability than commercial Novozym 435, obtaining an over $90 \%$ conversion rate after 20 cycles of recycling [13]. Hybrid magnetic cross-linked Candida antarctica lipase $\mathrm{B}$ aggregates showed outstanding thermal stability compared to the free lipase, retaining $60 \%$ of its initial activity after incubation at $60^{\circ} \mathrm{C}$ for $40 \mathrm{~min}$ [14]. Another enzyme, Aspergillus niger lipase (ANL) (EC. 3.1.1.3), has been used in the hydrolysis of fats to diglycerides, glycerol, free fatty acids, and monoglycerides $[15,16]$. Additionally, some studies also reported that the ANL was able to transform the olefins to epoxides with high catalytic rates, such as the biosynthesis of $\alpha$-pinene oxide from $\alpha$-pinene [17], and epoxidized methyl oleate from methyl oleate [18]. According to the above fact, this study chose ANL as a biocatalyst for the epoxidation of alkenes and discussed the catalytic performance of the immobilized ANL on the biosynthesis of epoxidation.

In this work, we firstly screened the optimal olefin substrates of the immobilized ANL for the production of epoxides. Moreover, the epoxidation reaction conditions of cyclooctene were assessed, including immobilized enzyme dose, reaction temperature, hydrogen peroxide dose, and substrate concentration. Furthermore, the operational stability of the immobilized ANL in the epoxidation reaction of cyclooctene was also evaluated.

\section{Results and Discussion}

\subsection{The Catalytic Performance of ANL@ZnGlu-MNPs on the Epoxidation of Different Substrates}

In order to determine the appropriate substrate, the epoxidation reactions of ANL@ZnGlu-MNPs were carried out with five kinds of olefins as the substrates, which were 2-phenyl-1-propene, 1-octene, 1-methyl-1-cyclohexene, styrene, and cyclooctene. As illustrated in Table 1, for the five substrates mentioned above, cyclooctene epoxidation obtained the maximum yield (47.2\%). However, the yield of 1-methyl-1-cyclohexene was the worst (only 17.9\%). In an aspect of enantiomeric excess, the epoxidation reactions of cyclooctene, styrene, and 1-methyl-1-cyclohexene showed the preferable optical purity of product at $80.4 \%, 85.8 \%$, and $86.1 \%$, respectively. Therefore, cyclooctene was selected for further study.

Table 1. Epoxidation of various olefins catalyzed by ANL@ZnGlu-MNPs.

\begin{tabular}{|c|c|c|c|}
\hline Olefins & Structure & Yield (\%) & e.e. $(\%)$ \\
\hline 1-octene & & 33.8 & $56.3(R)$ \\
\hline 2-phenyl-1-propene & & 27.6 & $70.1(S)$ \\
\hline cyclooctene & & 47.2 & $80.4(1 R, 2 R)$ \\
\hline styrene & & 23.4 & $85.8(S)$ \\
\hline 1-methyl-1-cyclohexene & & 17.9 & $86.1(1 R, 2 R)$ \\
\hline
\end{tabular}

Reaction conditions: ethyl acetate $4 \mathrm{~mL}$, various olefins $100 \mathrm{mM}$, ANL@ZnGlu-MNPs $75 \mathrm{mg}, \mathrm{H}_{2} \mathrm{O}_{2} 4.4 \mathrm{mmol}$, $200 \mathrm{rpm}, 40^{\circ} \mathrm{C}$.

The experimental data also suggested that the ANL can be used for the preparation of epoxides by the epoxidation of alkenes to achieve excellent optical purity of the product. In addition, this work indicated that an excellent enantiomeric excess (e.e.) could be obtained when the substrate contains significant steric hindrance of the group. However, the studied lipase showed a relatively low product yield compared to the typical lipase Novozym 435. For example, Novozym 435 can epoxidize a range of alkenes with the yield exceeding $75 \%$ [12]. Similarly, their results proved that excellent yields could be achieved when using cyclic olefins as substrate. 


\subsection{Effect of Substrate Concentrations on the Epoxidation of Cyclooctene by ANL@ZnGlu-MNPs}

Figure 1 displays the effect of substrate concentrations within the range from $25 \mathrm{mM}$ to $225 \mathrm{mM}$, on the oxidation of cyclooctene by ANL@ZnGlu-MNPs. Product e.e. declined slightly from $87.4 \%$ to $82.7 \%$, while substrate concentration improved, indicating that the cyclooctene concentration examined had little impact on the stereoselectivity of ANL@ZnGlu-MNPs. Differently, as the substrate concentration increased from $25 \mathrm{mM}$ to $150 \mathrm{mM}$, the initial rate of reaction was boosted from $10.7 \mathrm{mM} / \mathrm{h}$ to the maximum $15.6 \mathrm{mM} / \mathrm{h}$; nevertheless, the initial rate of reaction remarkably decreased and the concentration of cyclooctene continually rose. This result indicated that substrate inhibition occurred noticeably when the concentration of cyclooctene exceeded $150 \mathrm{mM}$. Furthermore, the highest yield of product could be achieved at $150 \mathrm{mM}$ of substrate concentration, while no significant change was found in the product yield with substrate concentration further increased. The results suggest that the reaction was mainly determined by the substrate inhibition but not product inhibition at the substrate concentrations examined. Consequently, $150 \mathrm{mM}$ of cyclooctene concentration was selected for further study.

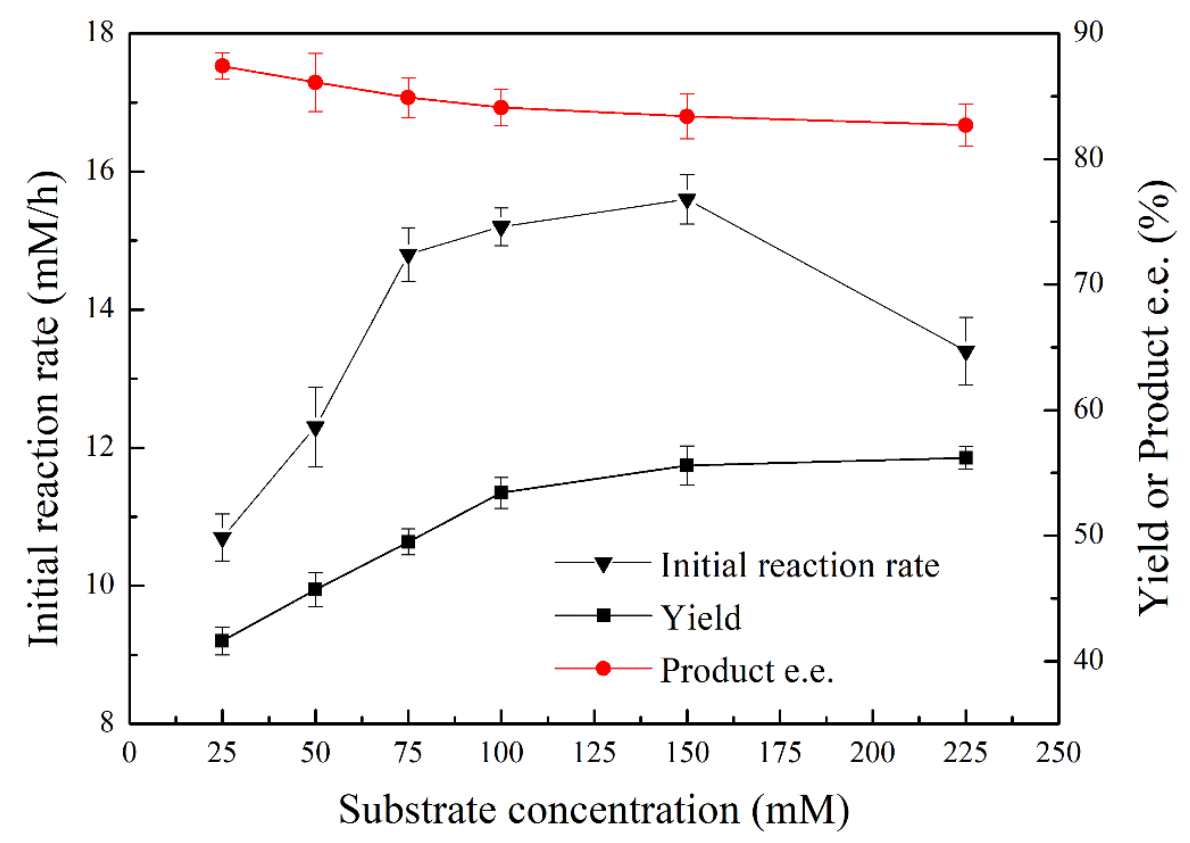

Figure 1. Effect of substrate concentration on epoxidation of cyclooctene catalyzed by ANL@ZnGlu-MNPs.

\subsection{Effect of Reaction Temperatures on the Epoxidation of Cyclooctene by ANL@ZnGlu-MNPs}

The impact of reaction temperature on the catalytic performance of ANL@ZnGlu-MNPs is shown in Figure 2. The tested reaction temperature affected the product e.e. values slightly but had a significantly impact on product yield and initial rate. The initial reaction rate gradually increased to the maximum as the temperature rose from $25^{\circ} \mathrm{C}$ to $40^{\circ} \mathrm{C}$. However, when the reaction temperature rose further, the initial rate of the reaction decreased rapidly. The results indicated that more than $40{ }^{\circ} \mathrm{C}$ of reaction temperature would accelerate the inactivation of ANL@ZnGlu-MNPs. The maximum of initial reaction rate and product yield could be achieved simultaneously at $40{ }^{\circ} \mathrm{C}$. 


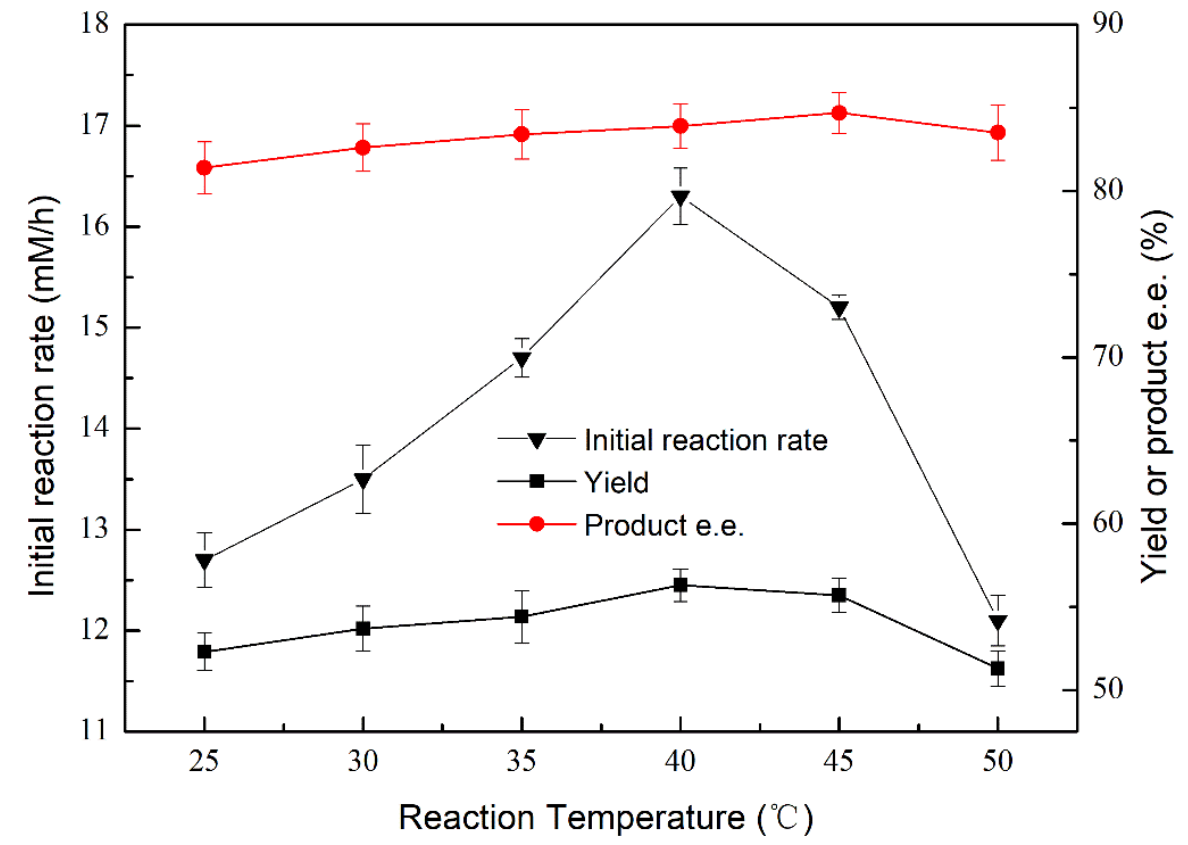

Figure 2. Effect of temperature on epoxidation of cyclooctene catalyzed by ANL@ZnGlu-MNPs.

Reaction temperature, as one of the essential factors for enzyme catalysis, not only had a dramatic impact on the number of active substrate molecules but also influenced the catalytic activity of the enzyme remarkably. Our results showed that the catalytic activity of lipase would be damaged if the reaction temperature exceeded $40{ }^{\circ} \mathrm{C}$. The yield of the product did not change much when the temperature ranged from $25{ }^{\circ} \mathrm{C}$ to $45^{\circ} \mathrm{C}$. However, when the reaction temperature reached 50 ${ }^{\circ} \mathrm{C}$, the yield of the product decreased significantly. This result may be explained in this way: the simultaneous action of hydrogen peroxide and high temperature led to the damage of the enzyme and the reduction of enzyme activity [19].

\subsection{Effect of ANL@ZnGlu-MNPs Doses on the Epoxidation of Cyclooctene}

Figure 3 reveals the effect of different doses of ANL@ZnGlu-MNPs on the epoxidation of cyclooctene. There was no significant change in e.e. value of the product at different immobilized enzyme doses. With the increase of enzyme dosage, the initial rate of the reaction gradually increased to the maximum. When the addition of immobilized enzyme exceeded $100 \mathrm{mg}$, the product yield would only change slightly. However, the product yield was notably lower with an enzyme dose less than $100 \mathrm{mg}$, demonstrating that the reaction was affected not only by the reaction time but also by the catalyst dose. The similar result suggests that the yield of ethyl (R)-3-hydroxybutyrate is also affected by the immobilized cell dose [20]. Other researchers, however, have found that there was no significant change in the yield of HMF at different biocatalyst doses [21]. Finally, we chose the concentration of $100 \mathrm{mg}$ as the best dosage of ANL@ZnGlu-MNPs. 


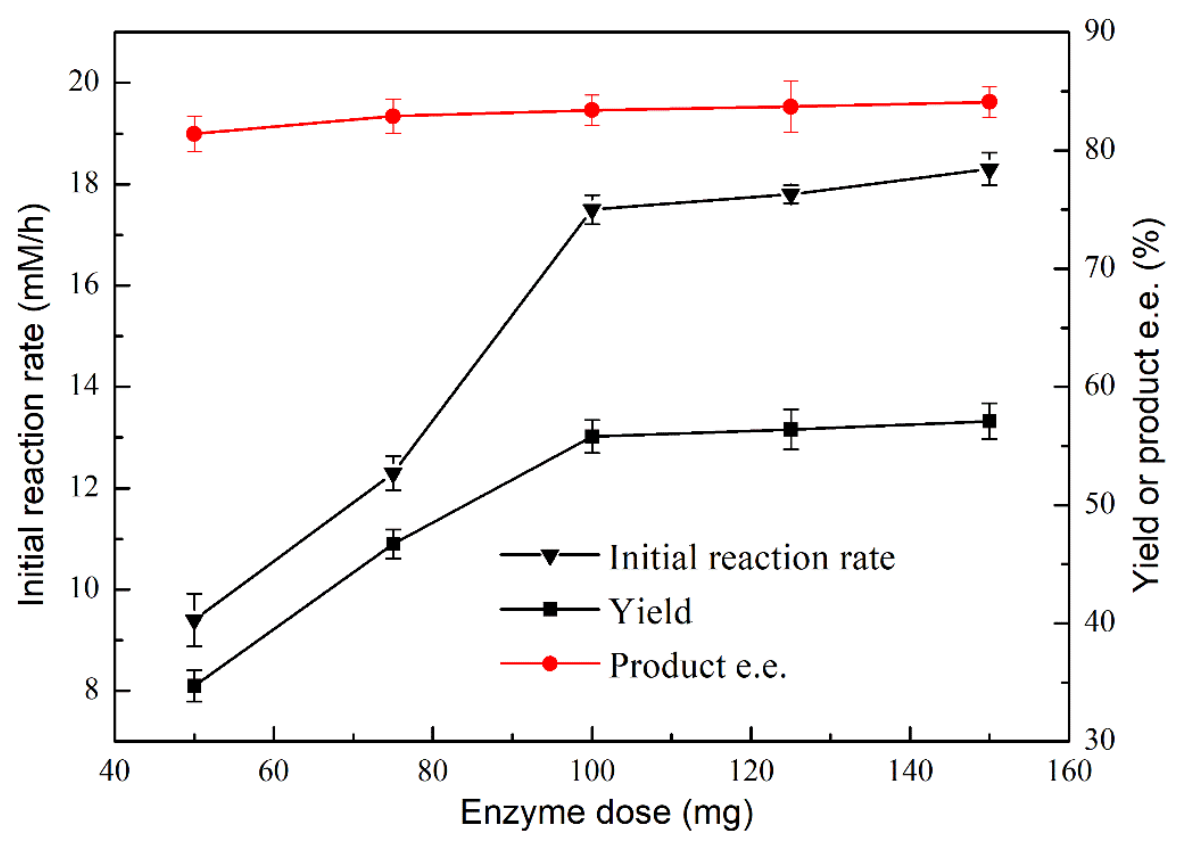

Figure 3. Effect of ANL@ZnGlu-MNPs dosage on epoxidation of cyclooctene catalyzed by ANL@ZnGlu-MNPs.

\subsection{Effect of $\mathrm{H}_{2} \mathrm{O}_{2}$ Doses on the Epoxidation of Cyclooctene by ANL@ZnGlu-MNPs}

Figure 4 shows the effect of $\mathrm{H}_{2} \mathrm{O}_{2}$ doses on the synthesis of $\mathrm{R}$-cyclooctene oxide. The dosage of hydrogen peroxide examined had only a marginal impact on the product optical purity. Our results showed that the amount of $\mathrm{H}_{2} \mathrm{O}_{2}$ had a remarkable effect on the initial reaction rate and product yield. The initial reaction rate and product e.e. value increased to the maximum with the increase in the amount of hydrogen peroxide from $1.1 \mathrm{mmol}$ to $4.4 \mathrm{mmol}$. Moreover, the further increase in the amount of $\mathrm{H}_{2} \mathrm{O}_{2}$ resulted in a decline of both of the two values mentioned above. The result indicates that adding more than $4.4 \mathrm{mmol}$ of hydrogen peroxide will destroy the activity of ANL@ZnGlu-MNPs.

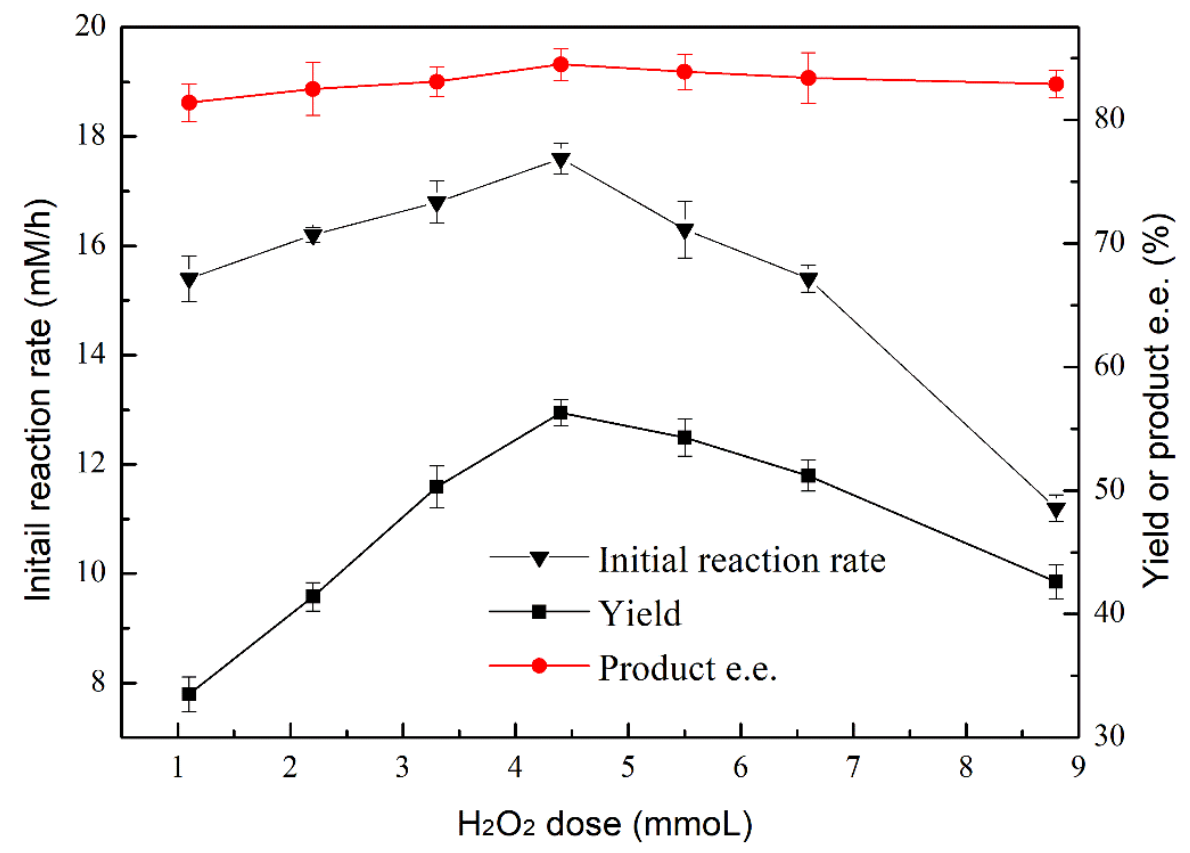

Figure 4. Effect of $\mathrm{H}_{2} \mathrm{O}_{2}$ dosage on epoxidation of cyclooctene catalyzed by ANL@ZnGlu-MNPs. 
$\mathrm{H}_{2} \mathrm{O}_{2}$, as an essential factor in the epoxidation reaction, can provide oxygen to start the reaction. However, excessive hydrogen peroxide can lead to inactivation of biocatalysts because of its strong oxidation capacity [22]. In addition, many side effects can be caused by the excessive addition of hydrogen peroxide. Finally, we chose to add the oxygenant in four batches to avoid the shortcomings mentioned above. The results showed that the initial rate and product yield of the reaction decreased significantly when the amount of hydrogen peroxide added to the reaction system exceeded $1.1 \mathrm{mmol}$. This result meant that the lipase used might be inactivated by adding more than $1.1 \mathrm{mmol}$ hydrogen peroxide in one step, resulting in a lower yield of the product. Moreover, when the total amount of hydrogen peroxide was more than $4.4 \mathrm{mmol}$, the product e.e. values decreased slightly with the increase of oxygenant, indicating that the side effects occurred. According to these results, we tended to inject hydrogen peroxide multiple times. Although these results differed from some published studies, which suggested that there was no difference in the product yield when hydrogen peroxide was added into the reaction system in one step or multiple steps, even higher initial reaction rates could be observed with one step of complete addition [23].

\subsection{Operational Stability of ANL@ZnGlu-MNPs}

As shown in Figure 5, the relative yield of ANL@ZnGlu-MNPs was still over 85\% when it was reused continuously for five batches, while with the increase of reuse times, the catalytic properties of the immobilized enzyme decreased significantly. For instance, when the immobilized enzyme was reused ten times, the relative product yield of the immobilized enzyme was approximately $52 \%$. Additionally, no significant change in the product e.e. was observed with the increase of recycling number, within the range from $82.5 \%$ to $84.5 \%$.

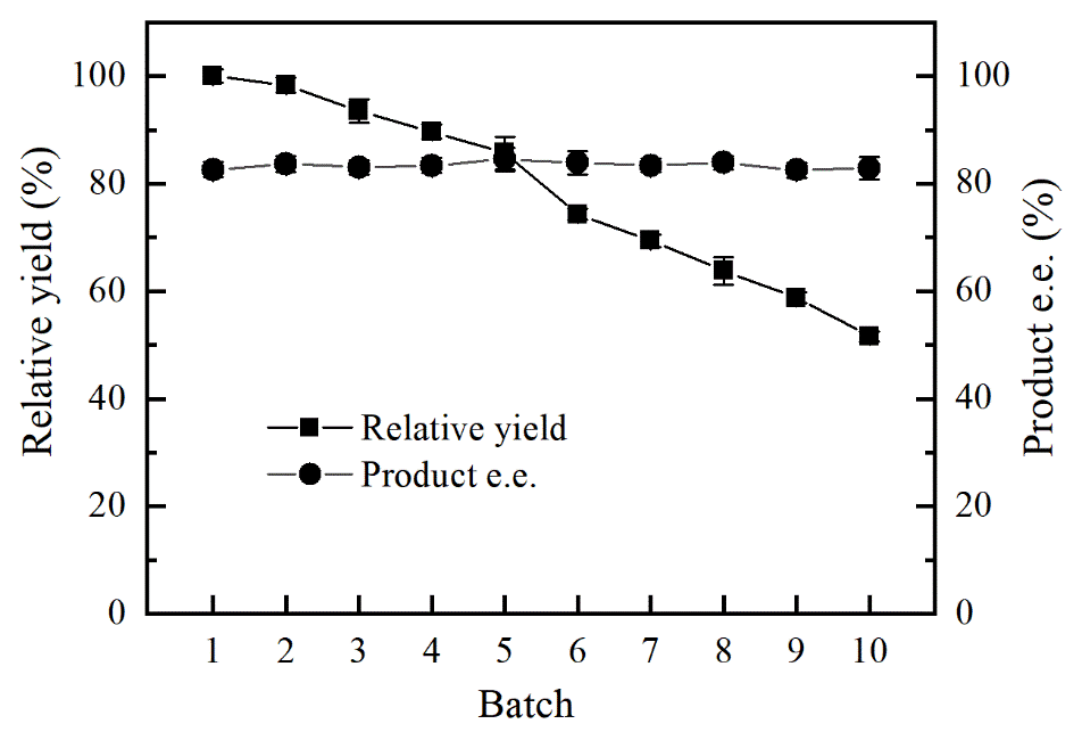

Figure 5. Operational stability of ANL@ZnGlu-MNPs in the epoxidation of cyclooctene.

The main advantages of enzyme immobilization are easy separation and stronger stability. The improvement of operational stability of an enzyme is a benefit for reducing the cost of the catalytic reaction. Comparison of our findings with those of other studies confirms that our immobilized lipase had better operational stability. For example, the catalytic yield of Candida antarctica lipase B immobilized in hydroxyl-propyl-methyl cellulose microemulsion-based organogels preserved only $25 \%$ of the initial yield when it was reused ten times [10], while the yield of ANL@ZnGlu-MNPs retained more than $50 \%$ of the initial yield after the same number of recycling times, as mentioned above. This result indicated that the catalytic activity of ANL was still partly affected by the components of the reaction system, although the ANL was immobilized. However, it also emphasized the necessity of ANL immobilization in industrial applications. 


\section{Material and Methods}

\subsection{Material}

Aspergillus niger lipase was purchased from Shenzhen Lvweikang Bio-Engineering Co. Ltd. (Shenzhen, China). The preparation of immobilized lipase (ANL@ZnGlu-MNPs) was referenced by our previous work [24]. Ethyl acetate was purchased from Sinopharm Chemical Reagent Co., Ltd. (Shanghai, China). Hydrogen peroxide and acetic acid were purchased from Chinasun Specialty Products Co., Ltd. (Jiangsu, China), and 2-phenyl-1-propene, 1-octene, 1-methyl-1-cyclohexene, styrene, and cyclooctene were purchased from Shaen Chemical Technology (Shanghai) Co., Ltd. (Shanghai, China). All reagents used in the study were from commercial sources and of analytical grade.

\subsection{Screening of Substrates}

The appropriate substrate for the epoxidation of ANL was sought from five olefins as follows: 2-phenyl-1-propene, 1-octene, 1-methyl-1-cyclohexene, styrene, and cyclooctene. Briefly, $100 \mathrm{mg}$ of ANL@ZnGlu-MNPs and $8.8 \mathrm{mmol}$ of acetic acid were mixed with $4 \mathrm{~mL}$ of ethyl acetate, and one of the above substrates $(0.6 \mathrm{mmol})$ was injected. The reactions were subsequently conducted in a constant temperature shaker at $40{ }^{\circ} \mathrm{C}$ and $200 \mathrm{rpm}$. During the reaction, hydrogen peroxide solution $(4.4 \mathrm{mmol}$ in total, $30 \%, w / w)$ was added four times within one hour to drive the reaction. No special annotation of hydrogen peroxide solution means that its concentration is $30 \%(w / w)$ and its amount is in total. Samples $(20 \mathrm{uL})$ were periodically withdrawn from the reaction mixture and extracted with the equal volume of ethyl acetate. $n$-Dodecane was used as the internal standard. After adequate extraction, the supernatants obtained by centrifugation at 13,000 rpm for 3 min were used for the analysis of product yields and enantiomeric excess (e.e.) values by gas chromatography.

\subsection{Reaction Parameter of ANL@ZnGlu-MNPs}

In the typical experiment, the reaction solvent consisting of ethyl acetate $(4 \mathrm{~mL})$ and acetic acid $(8.8 \mathrm{mmol})$ was contained in a 10-mL Erlenmeyer flask capped with a septum. The amount of immobilized ANL arranged from $50 \mathrm{mg}$ to $150 \mathrm{mg}$ was added. The above mixture was previously incubated in a constant temperature shaker at different temperatures $\left(25-50^{\circ} \mathrm{C}\right)$ and $200 \mathrm{rpm}$ for $15 \mathrm{~min}$. Then, the reaction was triggered by the addition of substrate at various amounts ( $25 \mathrm{mM}$ to $225 \mathrm{mM}$ ), and 1.1-8.8 mmol of hydrogen peroxide was added four times within one hour during the reaction. Samples $(20 \mathrm{uL})$ were periodically withdrawn from the reaction mixture and extracted with an equal volume of ethyl acetate. $\mathrm{N}$-dodecane was used as the internal standard. After adequate extraction, the supernatants obtained by centrifuging at 13,000 rpm for $3 \mathrm{~min}$ were used for the analysis of product yields and product e.e. values by gas chromatography.

\subsection{Operational Stability of ANL@ZnGlu-MNPs}

The reuse batch of the immobilized lipase in the epoxidation of cyclooctene was used to evaluate the operational stability. The evaluative reaction system comprised $4 \mathrm{~mL}$ of ethyl acetate, $8.8 \mathrm{mmol}$ of acetic acid, $0.6 \mathrm{mmol}$ of cyclooctene, $100 \mathrm{mg}$ of ANL@ZnGlu-MNPs, and $4.4 \mathrm{mmol}$ of hydrogen peroxide. The epoxidation reaction was conducted at $40{ }^{\circ} \mathrm{C}$ and $200 \mathrm{rpm}$ for $6 \mathrm{~h}$. In the meantime, $4.4 \mathrm{mmol}$ of hydrogen peroxide was added four times within one hour. After each batch, ANL@ZnGlu-MNPs was separated from the reaction medium by a magnet, washed thrice with ethyl acetate, and dried at $40^{\circ} \mathrm{C}$ for $30 \mathrm{~min}$. The dried immobilized enzyme was added to a fresh batch of reaction medium again. The product yield of each batch was analyzed, and the relative product yield of the first batch was defined as $100 \%$. 


\subsection{Analytical Methods}

The product was assayed for the e.e. values and yield using a Shimadzu 2010 gas chromatograph (Japan) equipped with a flame ionization detector and an HP-Chiral-10B (30 m $\times 0.25 \mathrm{~mm}$, Agilent, Santa Clara, CA, USA) chiral column. The carrier gas in GC analysis was nitrogen. The initial reaction rates were calculated according to the generated amount of product within a 30 min reaction. All experiments were repeated at least twice. The relative standard deviation was to be not be greater than $1 \%$, and the data were expressed as mean \pm standard deviation.

\section{Conclusions}

In this investigation, ANL@ZnGlu-MNPs was developed as an efficient and selective biocatalytic approach for the epoxidation reaction of cyclooctene and applied to synthesize chiral 1,2-epoxycyclooctene. ANL@ZnGlu-MNPs exerted excellent enantioselectivity and good operational stability for the epoxidation of cyclooctene. The enantiomeric excess rate of the product could reach more than $88 \%$ when it was reused for five batches. However, it probably still has enormous potential for increasing the product yield. Further study should be concentrated on the advancement of epoxide yield and the discovery of enzymes with highly efficient catalytic performance.

Author Contributions: Q.C., M.Z., and W.L. conceived and designed the experiments; Q.C. and F.P. performed the experiments with partial participation by Q.C. and G.X.; Q.C. analyzed the data and wrote the manuscript; F.L. revised the manuscript. All authors have read and agreed to the published version of the manuscript.

Funding: The authors are particularly grateful to the National Natural Science Foundation of China (21676104; 21878105), the National Key Research and Development Program of China (2018YFC1603400, 2018YFC1602100), the Science and Technology Program of Guangzhou (201904010360), the Key Research and Development Program of Guangdong Province (2019B020213001), and the Fundamental Research Funds for the Central Universities for partially funding this work.

Conflicts of Interest: The authors declare no conflict of interest.

\section{Abbreviations}

e.e.

ANL

ZnGlu

MNPs

ZnGlu-MNPs

ANL@ZnGlu-MNPs

\author{
enantiomeric excess \\ Aspergillus niger lipase \\ Zn-glutamate \\ magnetic iron oxide nanoparticles \\ ZnGlu-coated MNPs \\ ANL immobilized on ZnGlu-MNPs
}

\section{References}

1. Chen, W.J.; Lou, W.Y.; Zong, M.H. Efficient asymmetric hydrolysis of styrene oxide catalyzed by Mung bean epoxide hydrolases in ionic liquid-based biphasic systems. Bioresour. Technol. 2012, 115, 58-62. [CrossRef] [PubMed]

2. Wang, X.; Tang, Q.; Popowicz, G.M.; Yang, B.; Wang, Y. A mechanistic study into the epoxidation of carboxylic acid and alkene in a mono, di-acylglycerol lipase. Biochem. Biophys. Res. Commun. 2015, 460, 392-396. [CrossRef] [PubMed]

3. Nie, Y.; Xu, Y.; Mu, X.Q. Highly enantioselective conversion of racemic 1-phenyl-1,2-ethanediol by stereoinversion involving a novel cofactor-dependent oxidoreduction system of Candida parapsilosis CCTCC M203011. Org. Proc. Res. Dev. 2004, 8, 246-251. [CrossRef]

4. Cao, S.L.; Yue, D.M.; Li, X.H.; Smith, T.J.; Li, N.; Zong, M.H.; Wu, H.; Lou, W.Y. Novel nano-/micro-biocatalyst: Soybean epoxide hydrolase immobilized on UiO-66-NH2 MOF for efficient biosynthesis of enantiopure (R)-1,2-octanediol in deep eutectic solvents. ACS Sustain. Chem. Eng. 2016, 4, 3586-3595. [CrossRef]

5. Ren, W.M.; Liang, M.W.; Xu, Y.C.; Lu, X.B. Trivalent cobalt complex mediated formation of stereoregular $\mathrm{CO}_{2}$ copolymers from phenyl glycidyl ether. Polym. Chem. 2013, 4, 4425-4433. [CrossRef]

6. Louis, E.C.; Washington, N.J. Manufacture of 1,2-Epoxycyclooctane. U.S. Patent 2571208, 16 October 1951. 
7. Sheldon, R.A.; van Pelt, S. Enzyme immobilization in biocatalysis: Why, what and how. Chem. Soc. Rev. 2013, 42, 6223-6235. [CrossRef] [PubMed]

8. Tan, T.W.; Lu, J.; Nie, K.; Deng, L.; Wang, F. Biodiesel production with immobilized lipase: A review. Biotechnol. Adv. 2010, 28, 628-634. [CrossRef] [PubMed]

9. Aouf, C.; Durand, E.; Lecomte, J.; Figueroa-Espinoza, M.C.; Dubreucq, E.; Fulcrand, H.; Villenuve, P. The use of lipases as biocatalysts for the epoxidation of fatty acids and phenolic compounds. Green Chem. 2014, 16, 1740-1754. [CrossRef]

10. Zanette, A.F.; Zampakidi, I.; Sotiroudis, G.T.; Zoumpanioti, M.; Leal, I.C.R.; de Souza, R.O.M.A.; Cardozo-Filho, L.; Xenakis, A. Chemo-enzymatic epoxidation catalyzed by C. antarctica lipase immobilized in microemulsion-based organogels. J. Mol. Catal. B Enzym. 2014, 107, 89-94. [CrossRef]

11. Abdullah, B.M.; Salih, N.; Salimon, J. Optimization of the chemoenzymatic mono-epoxidation of linoleic acid using D-optimal design. J. Saudi Chem. Soc. 2014, 18, 276-287. [CrossRef]

12. Ankudey, E.G.; Olivo, H.F.; Peeples, T.L. Lipase-mediate epoxidation utilizing urea-hydrogen peroxide in ethyl acetate. Green Chem. 2006, 8, 923-926. [CrossRef]

13. Hua, X.; Ying, Y.; Zhang, X. Enhanced promiscuity of lipase-inorganic nanocrystal composites in the epoxidation of fatty acids in organic media. ACS Appl. Mater. Interfaces 2016, 8, 16257-16261. [CrossRef] [PubMed]

14. Cui, J.; Cui, L.; Jia, S.; Su, Z.; Zhang, S. Hybrid cross-linked lipase aggregates with magnetic nanoparticles: A robust and recyclable biocatalysis for epoxidation of oleic acid. J. Agric. Food Chem. 2016, 64, 7179-7187. [CrossRef]

15. Cao, S.L.; Huang, Y.M.; Li, X.H.; Xu, P.; Wu, H.; Li, N.; Lou, W.Y.; Zong, M. Preparation and Characterization of Immobilized Lipase from Pseudomonas Cepacia onto Magnetic Cellulose Nanocrystals. Sci. Rep. 2016, 6, 20420. [CrossRef]

16. Macrae, A.R.; Hammond, R.C. Present and future applications of lipases. Biotechnol. Genet. Eng. 1985, 3, 193-218. [CrossRef]

17. Tudorache, M.; Gheorghe, A.; Viana, A.S.; Parvulescu, V.I. Biocatalytic epoxidation of $\alpha$-pinene to oxy-derivatives over cross-linked lipase aggregates. J. Mol. Catal. B Enzym. 2016, 134, 9-15. [CrossRef]

18. Silva, W.S.D.; Lapis, A.A.M.; Suarez, P.A.Z.; Neto, B.A.D. Enzyme-mediated epoxidation of methyl oleate supported by imidazolium-based ionic liquids. J. Mol. Catal. B Enzym. 2011, 68, 98-103. [CrossRef]

19. Törnvall, U.; Orellana-Coca, C.; Hatti-Kaul, R.; Adlercreutz, D. Stability of immobilized Candida antarctica lipase B during chemo-enzymatic epoxidation of fatty acids. Enzym. Microb. Technol. 2007, 40, 447-451. [CrossRef]

20. Wang, X.T.; Chen, X.H.; Xu, Y.; Lou, W.Y.; Wu, H.; Zong, M.H. Biocatalytic anti-prelog stereoselective reduction of ethyl acetoacetate catalyzed by whole cells of Acetobacter sp. CCTCC M209061. J. Biotechnol. 2013, 163, 292-300. [CrossRef]

21. Li, Y.M.; Zhang, X.Y.; Li, N.; Xu, P.; Lou, W.Y.; Zong, M.H. Biocatalytic reduction of hmf to 2,5-bis(hydroxymethyl)furan by HMF-tolerant whole cells. ChemSusChem 2017, 10, 372. [CrossRef]

22. Vlček, T.; Petrović, Z.S. Optimization of the chemoenzymatic epoxidation of soybean oil. J. Am. Oil Chem. Soc. 2006, 83, 247-252. [CrossRef]

23. Orellana-Coca, C.; Camocho, S.; Adlercreutz, D.; Mattiasson, B.; Hatti-Kaul, R. Chemo-enzymatic epoxidation of linoleic acid: Parameters influencing the reaction. Eur. J. Lipid Sci. Technol. 2005, 107, 864. [CrossRef]

24. Xia, G.H.; Cao, S.L.; Xu, P.; Li, X.H.; Zhou, J.; Zong, M.H.; Lou, W.Y. Preparation of a nanobiocatalyst by efficiently immobilizing Aspergillus niger lipase onto magnetic metal-biomolecule frameworks (BioMOF). ChemCatChem 2017, 9, 1797-1800. [CrossRef]

(C) 2020 by the authors. Licensee MDPI, Basel, Switzerland. This article is an open access article distributed under the terms and conditions of the Creative Commons Attribution (CC BY) license (http://creativecommons.org/licenses/by/4.0/). 